\title{
Long-term effects of temperature and nutrient concentrations on the phytoplankton biomass in three lakes with differing trophic statuses on the Yungui Plateau, China
}

\author{
Jing Dong ${ }^{1,2, a}$, Qichao Zhou ${ }^{3,4, a}$, Yunni $\mathrm{Gao}^{2}$, Qianhong $\mathrm{Gu}^{2}$, Genbao $\mathrm{Li}^{1,{ }^{*}}$ and Lirong Song ${ }^{1}$ \\ ${ }^{1}$ State Key Laboratory of Freshwater Ecology and Biotechnology, Institute of Hydrobiology, Chinese Academy of Sciences, Wuhan \\ 430072, PR China \\ 2 College of Fisheries, Henan Normal University, Xinxiang 453007, PR China \\ 3 Yunnan Key Laboratory of Pollution Process and Management of Plateau Lake-Watershed, Yunnan Institute of Environmental Science \\ (Kunming China International Research Center for Plateau Lake), Kunming 650034, PR China \\ 4 Taihu Laboratory for Lake Ecosystem Research, State Key Laboratory of Lake Science and Environment, Nanjing Institute of \\ Geography and Limnology, Chinese Academy of Sciences, Nanjing 210008, PR China
}

Received: 21 February 2017; Accepted: 28 November 2017

\begin{abstract}
Long-term annual (1990-2010) monitoring data were analyzed to test the responses of phytoplankton biomass in three lakes in the Yungui Plateau, China, to increasing temperature and increasing nutrient concentrations. The three studied lakes (Lake Fuxian, Lake Erhai and Lake Dianchi) all exhibited significant increases in algal biomass from 1990 to 2010 , with increases of $0.111 \mu \mathrm{g} / \mathrm{L}, 0.662 \mu \mathrm{g} / \mathrm{L}$ and $3.07 \mu \mathrm{g} / \mathrm{L}$ per year, respectively. The study also indicated that the relative influences of warming and nutrient concentrations on chlorophyll a concentration varied among the lakes and was dependent on trophic level and phytoplankton composition. In Lake Fuxian, the increase in algal biomass was correlated with the rapid growth of Mougeotia spp., and the total phosphorous concentration was the key factor driving this increase in algal biomass. In Lake Erhai, the dominant species shifted from Dolichospermum spp. to Microcystis spp. Additionally, the increase in algal biomass in Lake Erhai (involving mainly an increase in Microcystis spp.) was significantly associated with an increase in total nitrogen (TN) concentration. In Lake Dianchi, warming and increases in TN concentration were the strongest predictors of biomass change.
\end{abstract}

Keywords: Phytoplankton ecology / warming / eutrophication / algal biomass increase

\section{Introduction}

In recent decades (especially since the 1990s), numerous lakes worldwide have shifted from an aquatic vegetationdominated clear state to a phytoplankton-dominated turbid state. Water transparency has greatly reduced during this process, and the landscape and drinking water values of affected lakes have sharply decreased. Although many studies have been conducted on this topic, the primary factors that promote phytoplankton development remain debated and require further elucidation (Elliott et al., 2006; Wagner and Adrian, 2009; Jeppesen et al., 2010; Elliott, 2012; Zhang et al., 2012; Rigosi et al., 2014). Nevertheless, it is commonly assumed that eutrophication and climate change associated with anthropogenic activities are

\footnotetext{
*Corresponding author: ligb@ihb.ac.cn

${ }^{\mathrm{a}} \mathrm{Co}$-first authors.
}

major threats to lake ecosystems and are the main factors driving phytoplankton development (e.g., cyanobacterial blooms).

Previous studies have revealed the interactive effects of increased nutrient concentrations and warming in promoting the frequency and magnitude of cyanobacterial blooms (Jöhnk et al., 2008; Paerl and Huisman, 2009; Liu et al., 2011; Huber et al., 2012; O'Neil et al., 2012; Paerl and Paul, 2012; Gkelis et al., 2014). Additionally, Elliott (2012) reported that climate warming can accelerate the negative effects of eutrophication on aquatic ecosystems, whereas nutrient dilution alleviates the adverse effects of climate warming on lake systems. However, the factor that exerts the predominant effects on phytoplankton abundance and biomass in lake systems remains unclear. In an open-air microcosm study (at the University of Liverpool Botanic Gardens at Ness on the Wirral Peninsula, UK), Moss et al. (2003) found that eutrophication was a major factor that influenced algal abundance and that the effects of climate warming on phytoplankton in shallow lakes were negligible. In Lake Müggel, cyanobacteria were found to not directly benefit 
Table 1. Characteristics of Lake Fuxian (Gao et al., 2013), Lake Erhai (Li et al., 2015) and Lake Dianchi (Zhou et al., 2016).

\begin{tabular}{llll}
\hline & Lake Fuxian & Lake Erhai & Lake Dianchi (Waihai) \\
\hline Latitude & $24^{\circ} 21^{\prime} 28^{\prime \prime}-24^{\circ} 38^{\prime} \mathrm{N}$ & $25^{\circ} 36^{\prime}-25^{\circ} 58^{\prime} \mathrm{N}$ & $24^{\circ} 30^{\prime}-25^{\circ} 02^{\prime} \mathrm{N}$ \\
Longitude & $102^{\circ} 49^{\prime} 12^{\prime \prime}-102^{\circ} 57^{\prime} 26^{\prime \prime} \mathrm{E}$ & $100^{\circ} 05^{\prime}-100^{\circ} 17^{\prime} \mathrm{E}$ & $102^{\circ} 36^{\prime}-102^{\circ} 47^{\prime} \mathrm{E}$ \\
Nutrition status & Oligotrophic & Mesotrophic & Eutrophic \\
Surface area $\left(\mathrm{km}^{2}\right)$ & 212 & 252.91 & 298.2 \\
Maximal depth (m) & 157.3 & 21.5 & 11.2 \\
Mean depth (m) & 87 & 10.8 & 4.4 \\
\hline
\end{tabular}

from warming; rather, nutrient reductions caused a bloom decline (Köhler et al., 2005; Wagner and Adrian, 2009). Additionally, Anneville et al. (2005) analyzed monitoring data from European plateau lakes from 1974 to 2000 and showed that the phosphorous level was the key determinant of algal composition. Additionally, Brookes and Carey (2011) suggested that controlling nutrients is extremely important for increasing the resilience of aquatic ecosystems to cyanobacterial blooms. In a study of 143 lakes ranging from subarctic Europe to southern South America, Kosten et al. (2012) showed that the percentage of the total phytoplankton biovolume attributable to cyanobacteria increased steeply with temperature. Furthermore, Paerl and Huisman (2008) and Posch et al. (2012) indicated that warming played a more important role than nutrient level increases in promoting cyanobacterial blooms.

The influences of eutrophication, climate change or other main and interactive effects on algal growth are complex, debated and difficult to predict (Brookes and Carey, 2011). In many recent studies, lake type, lake nutrient level and species composition have been used to predict the responses of phytoplankton to changes in nutrients and climate. Previous studies have indicated that temperature is a key factor in determining cyanobacterial abundance in stratified bodies of water (Becker et al., 2010; Taranu et al., 2012), whereas nutrient levels, such as the total phosphorous (TP) concentration, are important determinants of the cyanobacterial biomass of mixed bodies of water (Wagner and Adrian, 2009; Taranu et al., 2012). According to the 31-year monitoring data set from Lake Geneva presented by Tadonléké (2010), phytoplankton exhibited positive responses to warming when the TP concentration in the lake water exceeded $0.022 \mathrm{mg} / \mathrm{L}$ (eutrophic conditions), whereas negative responses were observed at low TP concentrations (nutrient-poor conditions). Furthermore, some studies have suggested that the sensitivity of cyanobacterial abundance to temperature and nutrients depends on the species composition (Rigosi et al., 2014; Deng et al., 2016). Taxa such as Dolichospermum spp. are more sensitive to nutrients, whereas Microcystis is more sensitive to temperature.

Lake Fuxian, Lake Erhai and Lake Dianchi, which are located on the Yungui Plateau, China, are the main local water resources, providing potable water for Yuxi City, Dali City and Kunming City, respectively. Currently, the three lakes are undergoing different increases in nutrition concentrations and rapid algal growth. Although nutrient enrichment has been commonly identified as a key predictor of phytoplankton development and dominance in freshwater, warming also plays a role (Zhou et al., 2015). The driving force of phytoplankton biomass change has not yet been studied in these three lakes. Quantifying and analyzing the variability in lake responses to environmental changes will provide crucial information for lake assessments, which are important for lake management and protection. In the present study, the following are investigated: (1) temporal changes in the environmental variables and algal biomass of the three lakes, each having a different trophic status; (2) the key environmental factors correlated with phytoplankton biomass in each lake; and (3) the role of phytoplankton composition in the responses of each lake to environmental variables. Here, the functional group concept is applied, as this method can precisely predict species occurrence and reflect habitat characteristics (Reynolds et al., 2002; Padisák et al., 2009).

\section{Methods}

\subsection{Descriptions of the three lakes}

Lake Fuxian (area $21 \mathrm{~km}^{2}$, maximum depth $157.3 \mathrm{~m}$, mean depth $87 \mathrm{~m}$ ) (Tab. 1) is the second-deepest lake in central Yunnan Province, China. The lake is in a subtropical zone with a monsoon climate and an annual precipitation of approximately $800-1100 \mathrm{~mm}$ (Gao et al., 2013). Currently, the lake is oligotrophic.

Lake Erhai (area $252.91 \mathrm{~km}^{2}$, maximum depth $21.5 \mathrm{~m}$, mean depth $10.8 \mathrm{~m}$ ) (Tab. 1) is the second largest freshwater lake in Yunnan Province, China. This lake, characterized by a plateau mountain and monsoon climate, is a vital potable water source for Dali city. With the rapid development of industry and agriculture in the region, the lake has been subjected to serious pollution since the 1980s. The lake is now mesotrophic.

Lake Dianchi, located in southwestern China and characterized by a subtropical plateau mountain monsoon climate, is the largest freshwater lake in Yunnan Province. Lake Dianchi covers $309 \mathrm{~km}^{2}$ and is partitioned into two sections: Caohai Lake (area $10.8 \mathrm{~km}^{2}$ ) in the north and Waihai Lake $\left(298.2 \mathrm{~km}^{2}\right)$ in the south (Zhou et al., 2016). The present study focuses on Waihai, a typical eutrophic lake in China that has experienced cyanobacterial blooms since the 1990s (Sheng et al., 2012; Li et al., 2014).

All three lakes studied here have different nutrient levels and are located on the Yungui Plateau, China. The locations of the three lakes are shown in Figure 1.

\subsection{Data collection}

Water quality data, including algae biomass (characterized by chlorophyll a concentration (Chl. a)), water transparency (SD), total nitrogen (TN) and TP concentrations, for Fuxian Lake from 1990 to 2010 were originally obtained from the 


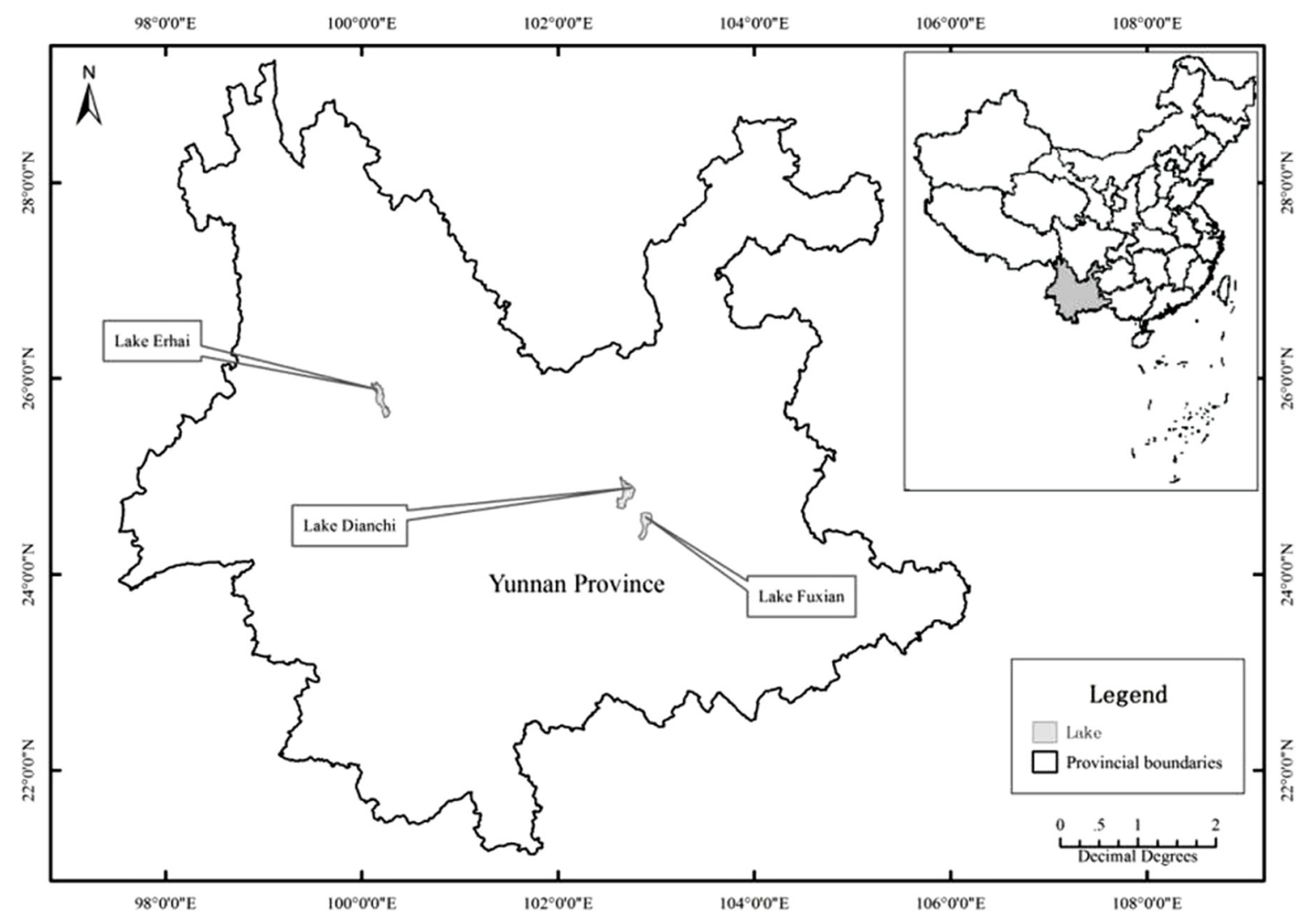

Fig. 1. The locations of Lakes Fuxian, Erhai and Dianchi in Yunnan Province, China.

Yuxi Institute of Environmental Science and Yuxi Environmental Monitoring Center (Gao et al., 2013). The water quality data for Erhai Lake (1990-2010) were obtained from the Erhai Authority (Fu et al., 2013), and the data for Dianchi Lake (1990-2007) were collected from the Kunming Environmental Monitoring Center (Yu et al., 2013; Ouyang et al., 2015; Zhou et al., 2016). The air temperature data (AT) for areas surrounding Lake Fuxian, Lake Erhai and Lake Dianchi were obtained from the meteorological information center of each local city (Dong et al., 2008, 2012; Gu, 2008; Huang et al., 2010). Between 2008 and 2010, the environmental variable data and phytoplankton data from Lake Dianchi were obtained by the present authors, with sampling performed according to Dong et al. (2015). In each year, water was sampled each month to determine the algal biomass and the levels of environmental variables. A Secchi disk was used to evaluate the SD of each water body. The TN, TP and Chl. a concentrations were measured according to the Protocols for Standard Observation and Measurement in Aquatic Ecosystems of the Chinese Ecosystem Research Network (CERN) (Huang et al., 2000; Cai 2007). All the annual data were calculated based on 12-month (24 sampling sites) averages. The dominant phytoplankton compositions in the three lakes were obtained from our previous study (Dong et al., 2014).

\subsection{Statistical analysis}

Data exploration was performed before data analysis. Time series analyses of Chl. $a$, TP, TN, SD and AT were conducted to identify long-term trends related to AT and water quality data, and temporal autocorrelation was assessed for all the variables using an autocorrelation function. Then, Spearman correlation analyses were conducted to identify the correlations between all potential pairs of variables (standardized values) in each lake. Finally, stepwise regression of $\operatorname{Ln}(\mathrm{Chl} . a+1)$ on $\operatorname{Ln}(\mathrm{AT}+1)$, $\operatorname{Ln}$ $(\mathrm{SD}+1), \operatorname{Ln}(\mathrm{TN}+1)$ and $\mathrm{Ln}(\mathrm{TP}+1)$ was performed for each lake to determine the main explanatory variables; the significant variables in the model were selected based on $t$-tests. Additionally, the standardized beta coefficient was used to estimate the relative contribution of each environmental factor to the phytoplankton biomass. The analyses were performed with IBM SPSS Statistics (version 22.0).

\section{Results}

\subsection{Long-term trends in environmental variables in Lakes Fuxian, Erhai and Dianchi}

The variations in mean AT were more pronounced in Lake Erhai and Lake Dianchi than those in Lake Fuxian (Fig. 2). The surrounding ATs of Lake Erhai (slope $=0.075, p<0.01$, Tab. 2) and Dianchi (slope $=0.071, p<0.01$, Tab. 2) increased significantly from 1990 to 2010. However, no significant increase in temperature near Lake Fuxian was detected $(p>0.05)$ over the studied time period.

Significant TN increases of $0.017 \mathrm{mg} / \mathrm{L}$ and $0.434 \mathrm{mg} / \mathrm{L}$ per year were observed from 1990 to 2010 in Lakes Erhai and Dianchi, respectively (Tab. 2). In contrast, no significant 
Lake Fuxian
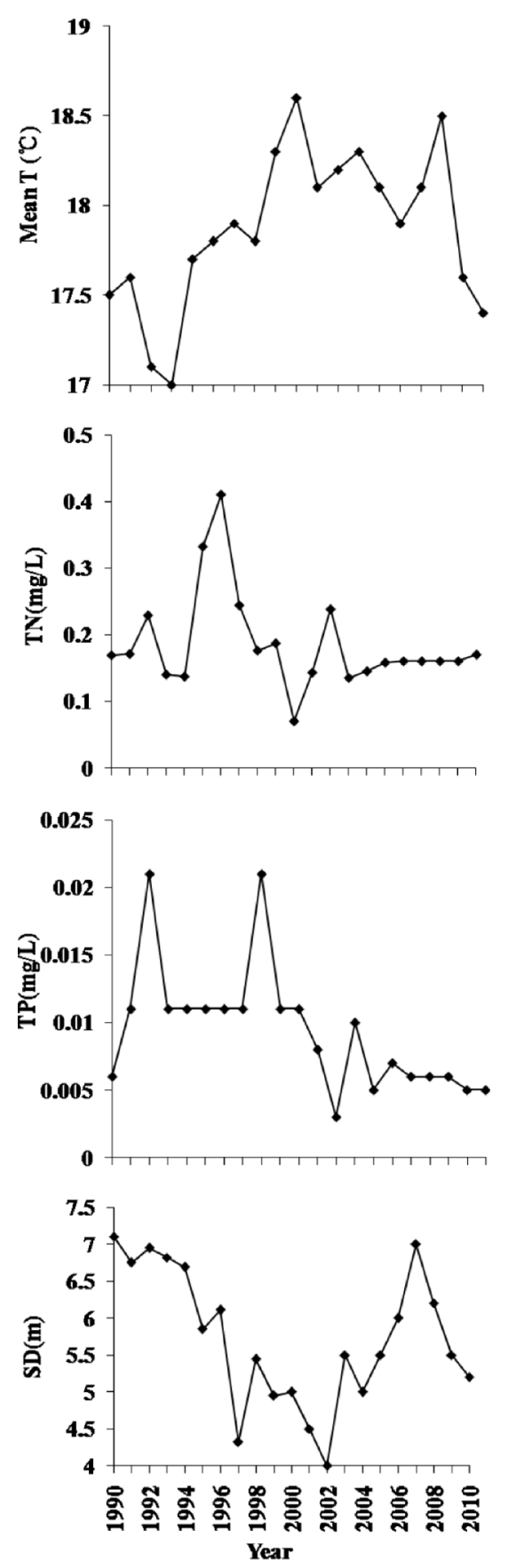

Lake Erhai
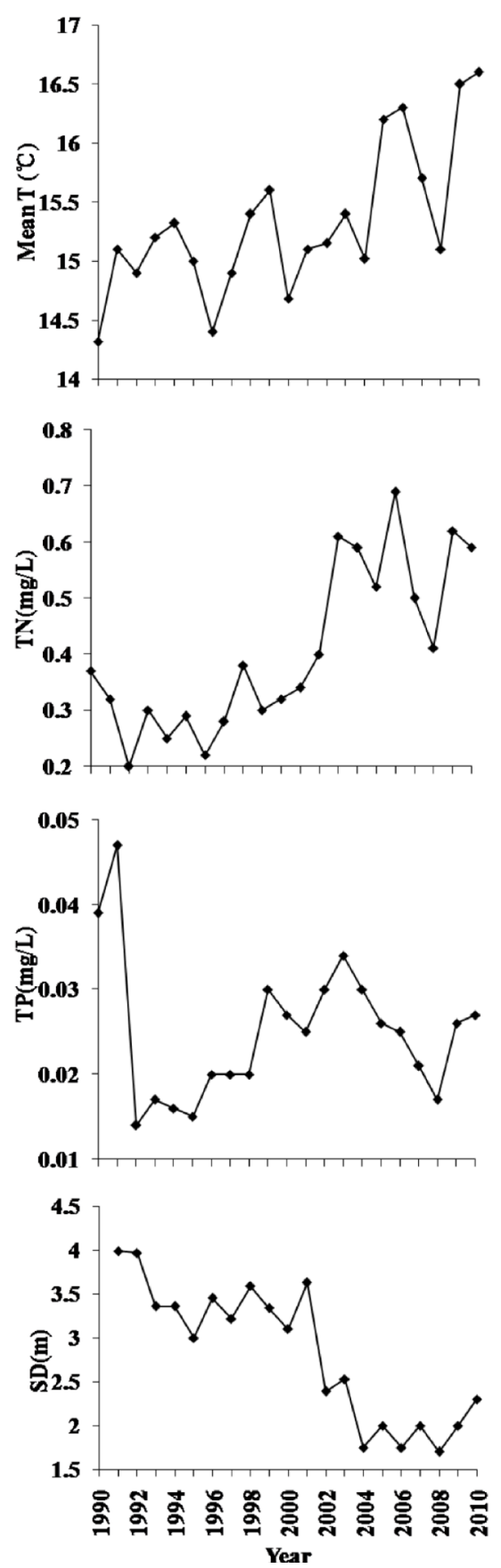

Lake Dianchi
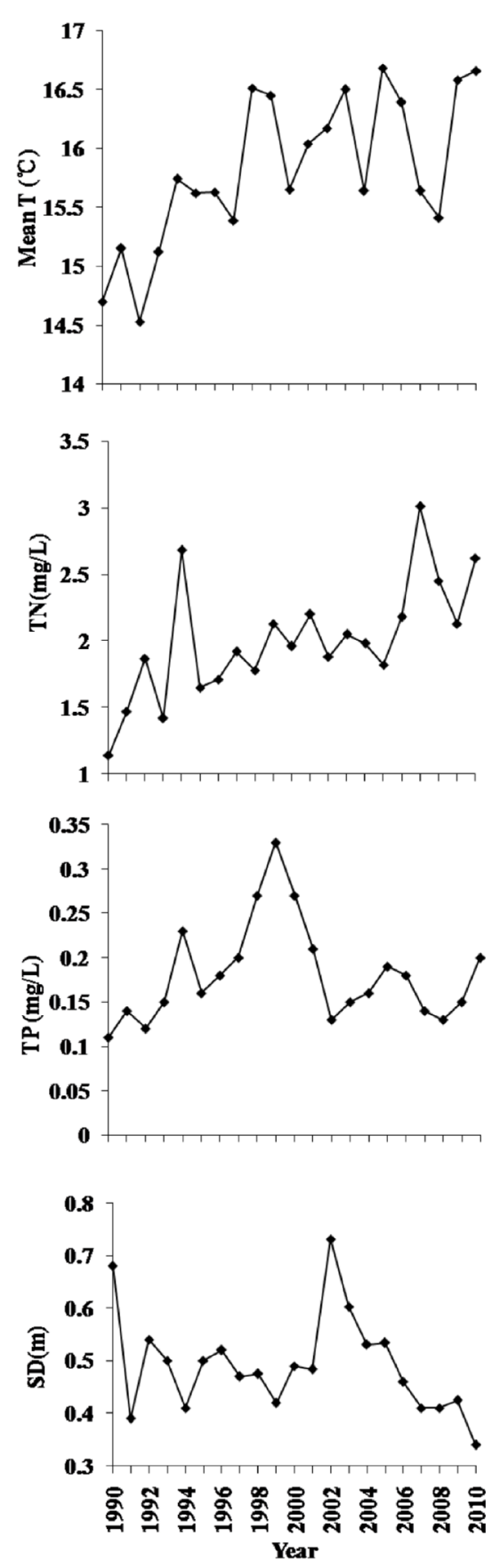

Fig. 2. Trends in environmental variables in Lakes Fuxian, Erhai and Dianchi from 1991 to 2010 (AT, annual mean air temperature; SD, annual mean water transparency; TN, annual mean total nitrogen; TP, annual mean total phosphorus).

change in TN concentration was detected for Lake Fuxian over the time period under study. However, from 1990 to 1996, an obvious increase in TN concentration in Lake Fuxian was detected, with a peak in 1996 (0.41 mg/L) (Fig. 2).

An obvious decrease in TP concentration in Lake Fuxian was observed. The TP concentration decreased by $0.0004 \mathrm{mg} /$ L between 1990 and 2010 (Tab. 2). No significant change in TP concentration from 1990 to 2010 was observed for Lakes Erhai and Dianchi; however, a significant increase was observed in
Lake Erhai from 1992 to $2003(0.0017 \mathrm{mg} / \mathrm{L}$ per year, $p<0.01)$. Thereafter, an obvious decrease of $0.0012 \mathrm{mg} / \mathrm{L}$ per year $(p<0.01)$ occurred in the lake. The TP concentration of Lake Dianchi exhibited trends similar to those of Lake Erhai, including a significant increase of $0.021 \mathrm{mg} / \mathrm{L}$ per year from 1991 to 1999 and a decrease of $0.01 \mathrm{mg} / \mathrm{L}$ per year from 1999 to 2010 ( $p<0.01)$ (Fig. 2).

There were no significant changes in SD for Lake Fuxian and Lake Dianchi from 1990 to 2010 . In contrast, the SD of 
Table 2. Linear regressions between each variable over the study period.

\begin{tabular}{llllll}
\hline Lake & Variable & Slope & $p$ & $N$ & Year range \\
\hline \multirow{5}{*}{ Fuxian } & Chl. $a^{*}$ & 0.111 & $<0.01$ & $20^{*}$ & $1990-2010$ \\
& AT* & - & $>0.05$ & $20^{*}$ & $1990-2010$ \\
& SD $^{*}$ & - & $>0.05$ & $20^{*}$ & $1990-2010$ \\
& TN* & - & $>0.05$ & $20^{*}$ & $1990-2010$ \\
& TP & -0.0004 & $<0.01$ & 21 & $1990-2010$ \\
& & & & & \\
& Chl. $a^{*}$ & 0.662 & $<0.05$ & $20^{*}$ & $1990-2010$ \\
& AT* & 0.075 & $<0.01$ & $20^{*}$ & $1990-2010$ \\
& SD & -0.115 & $<0.01$ & 20 & $1991-2010$ \\
& TN* & 0.017 & $<0.01$ & $20^{*}$ & $1990-2010$ \\
& TP* & - & $>0.05$ & $20^{*}$ & $1990-2010$ \\
& & & & & \\
& Chl. $a^{*}$ & 3.07 & $<0.05$ & $20 *$ & $1991-2010$ \\
& AT & 0.071 & $<0.01$ & 21 & $1990-2010$ \\
Dianchi & SD & - & $>0.05$ & 21 & $1990-2010$ \\
& TN & 0.434 & $<0.01$ & 21 & $1990-2010$ \\
& TP* & - & $>0.05$ & $20 *$ & $1990-2010$ \\
\hline
\end{tabular}

Chl. $a$, annual mean chlorophyll $a$ concentration; AT, annual mean air temperature; SD, annual mean water transparency; TN, annual mean total nitrogen; and TP, annual mean total phosphorus. "*” indicates that there was an temporal autocorrelation in the ordinary regression, as demonstrated using modified linear models by autoregression (AR-1).

Lake Erhai markedly decreased $(0.115 \mathrm{~m}$ per year, $p<0.01)$ from 1991 to 2010 (Tab. 2). In Lake Fuxian, SD decreased by $0.27 \mathrm{~m}$ over this period, although it increased by $0.15 \mathrm{~m}$ per year after 2002. The SD of Lake Dianchi exhibited a significant decrease from 2002 to $2010(0.041 \mathrm{~m}$ per year, $p<0.01)$ (Fig. 2).

\subsection{Long-term trends in the phytoplankton biomass (Chl. a) levels in Lakes Fuxian, Erhai and Dianchi}

Significant increases in Chl. $a$ concentration were observed for Lake Fuxian (slope $=0.111, p<0.01$, Tab. 2), Lake Erhai (slope $=0.662, p<0.05$, Tab. 2) and Lake Dianchi (slope $=$ $3.07, p<0.05$, Tab. 2) over the time period under study. The between-year variation in Chl. $a$ was most pronounced in Lake Dianchi (Tab. 2; Fig. 3).

\subsection{Variations in Chl. a and its driving factors in Lakes Fuxian, Erhai and Dianchi}

The relationships between pairs of variables, as determined from Spearman correlation analysis, are shown in Table 3. Chl. $a$ content was significantly correlated with TP concentration in Lake Fuxian; AT and TN concentration (particularly the latter) in Lake Erhai; and TP, AT and TN concentration (particularly AT and TN) in Lake Dianchi. Based on the stepwise regression of $\operatorname{Ln}(\mathrm{Chl} . a+1)$ against $\operatorname{Ln}(\mathrm{AT}+1), \operatorname{Ln}(\mathrm{SD}+1), \operatorname{Ln}(\mathrm{TN}+1)$ and $\operatorname{Ln}(\mathrm{TP}+1)$ for Lake Fuxian, TP was the main contributing factor to phytoplankton biomass $(p<0.05)$. This relationship is described by the model as shown in Table 4 . The significant driving factors affecting Chl. $a$ in Lake Erhai were TN concentration $(p<0.05)$ and $\mathrm{SD}(p<0.05)$. For Lake Dianchi, AT $(p<0.01)$ and TN concentrations $(p<0.05)$ were the significant driving factors (Tab. 4; Fig. 4).

\subsection{Phytoplankton variation in the three lakes from 1990 to 2010}

According to our previous study (Dong et al., 2014), the dominant species in Lake Fuxian are Mougeotia spp. (phytoplankton group T). Moreover, the dominant species in Lake Erhai shifted from Cyclotella sp. (C), Aphanizomenon flos-aquae (H1), and Anabaena sporoides (H1) to Microcystis flos-aquae (M). In Lake Dianchi, the dominant species shifted from green algae Pediastrum sp. (J) and Scenedesmus sp. (J) to Microcystis flos-aquae (M).

\section{Discussion}

In Lakes Erhai and Dianchi, the nutrient levels varied significantly over the period under study. The TN concentrations in Lake Erhai and Lake Dianchi increased over the study period. However, we did not detect significant changes in TP concentration in Lake Erhai or Lake Dianchi from 1990 to 2010. Previous studies have shown that nutrient increases drive increases in algal biomass (Moss et al., 2003; Köhler et al., 2005; Wagner and Adrian, 2009). Accordingly, such increases considerably influenced algal biomass in these two lakes. To determine the role of warming, we focused on the ATs of these two lakes. We found that Lake Erhai and Lake Dianchi experienced climate warming, with temperature increases of $0.075^{\circ} \mathrm{C}$ and $0.071^{\circ} \mathrm{C}$ per year, respectively, from 1990 to 2010. This finding is in accordance with the findings of Coumou et al. (2013) and Deng et al. (2016), who reported that the mean AT of Lake Taihu increased by $0.065^{\circ} \mathrm{C}$ per year from 1992 to 2013. In our study, the Spearman correlation analysis indicated that the increases in algal biomass in the two lakes were significantly correlated with both temperature and TN concentration. This result is in agreement with the results of Mooij et al. (2005) and Elliott (2012), who suggested that climate warming and eutrophication play vital roles in phytoplankton structuring and are important indicators of phytoplankton dynamics. However, it remains unclear which factor is more important and the best predictor of algal biomass. In the present study, the stepwise regression analyses indicated that algal biomass was associated with TN concentration in Lake Erhai and with AT and TN concentration in Lake Dianchi. This difference might be related to differences in species composition between the two lakes. Different species react differently to climate change and eutrophication, and their tolerance to key environmental factors differs (Adrian et al., 2006; Feuchtmayr et al., 2012; Walters et al., 2013; Rigosi et al., 2014).

In Lake Erhai, the dominant cyanobacterial species changed significantly over the study period of 1990-2010. A cyanobacterial bloom first occurred in 1996, and Dolichospermum sp. was predominant from 1996 to 2006. Our previous studies (details in Dong et al., 2014) indicated that the dominance of Microcystis has become increasingly pronounced in recent years, and the overwhelmingly dominant 
Lake Fuxian

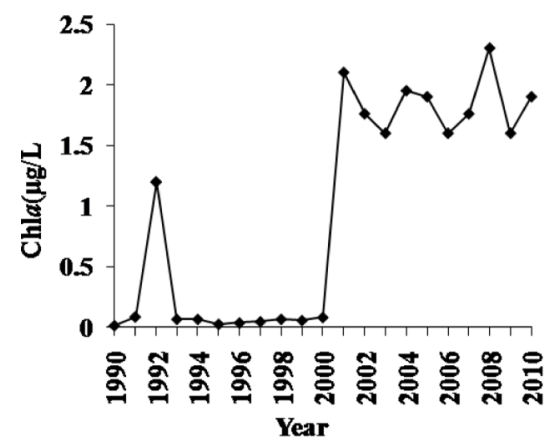

Lake Erhai

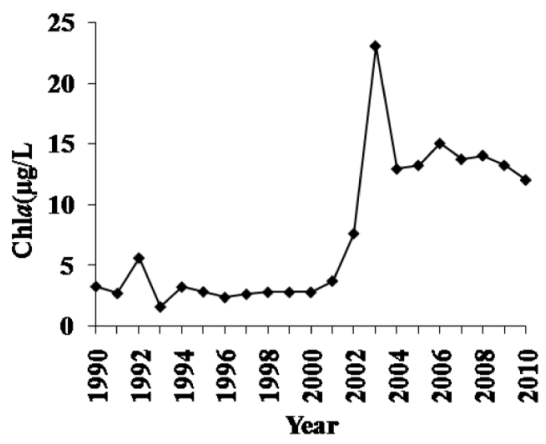

Lake Dianchi

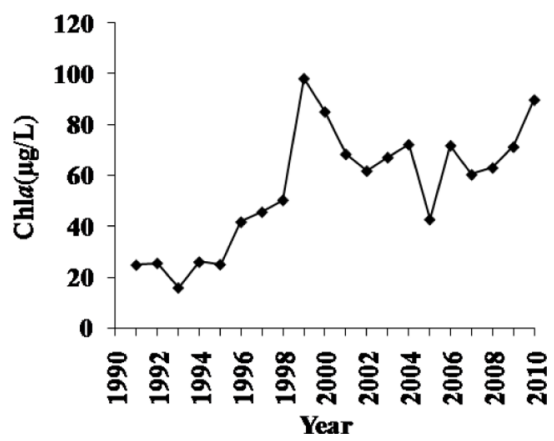

Fig. 3. Trends in the annual mean chlorophyll $a$ (Chl. a) concentrations in Lakes Fuxian, Erhai and Dianchi from 1991 to 2010.

Table 3. Spearman correlations between the standardized variables of the three lakes.

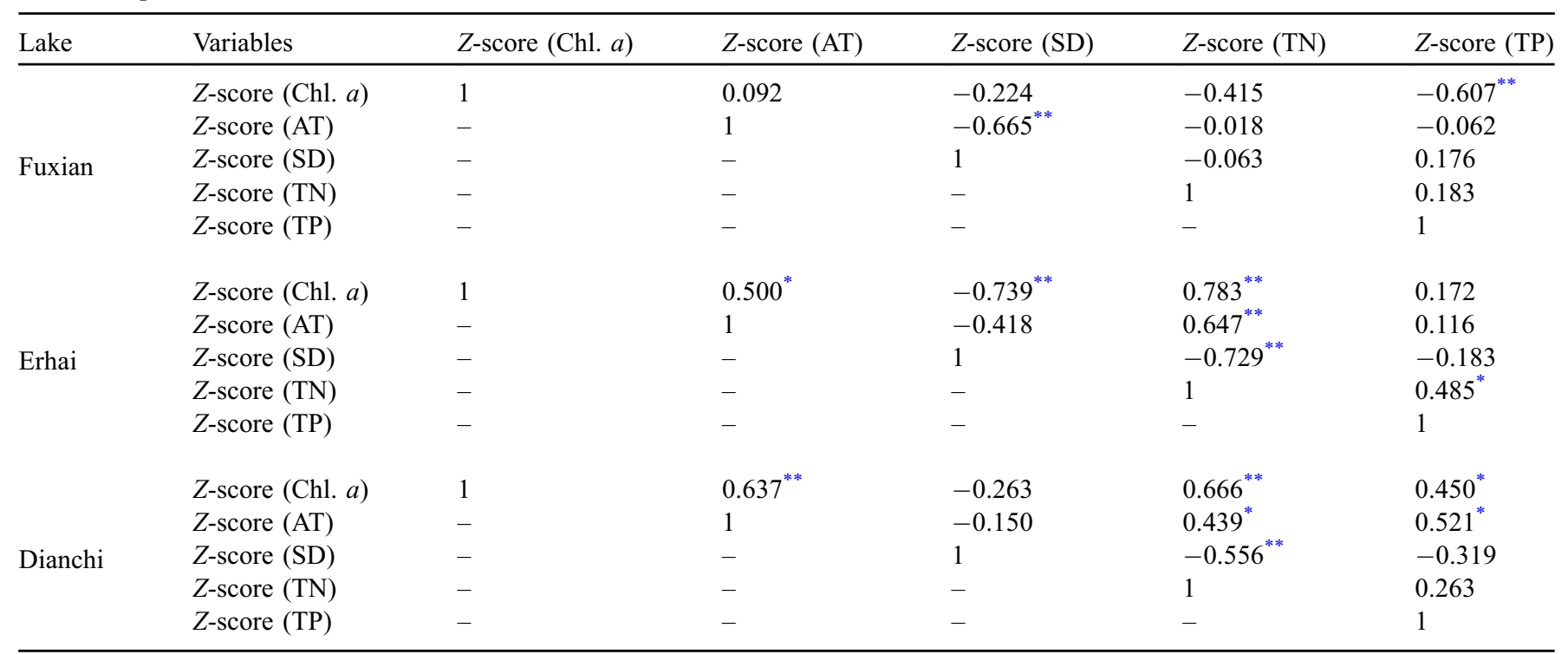

$Z$-score, standardized values. Chl. $a$, annual mean chlorophyll $a$ concentration; AT, annual mean air temperature; SD, annual mean water transparency; TN, annual mean total nitrogen; and TP, annual mean total phosphorus.

* Significance at $p<0.05$.

${ }^{* *}$ Significance at $p<0.01$.

Table 4. Stepwise regression between $\operatorname{Ln}(\mathrm{Chl} . a+1)$ and $\operatorname{Ln}(\mathrm{AT}+1), \operatorname{Ln}(\mathrm{SD}+1), \operatorname{Ln}(\mathrm{TN}+1)$ and $\operatorname{Ln}(\mathrm{TP}+1)$.

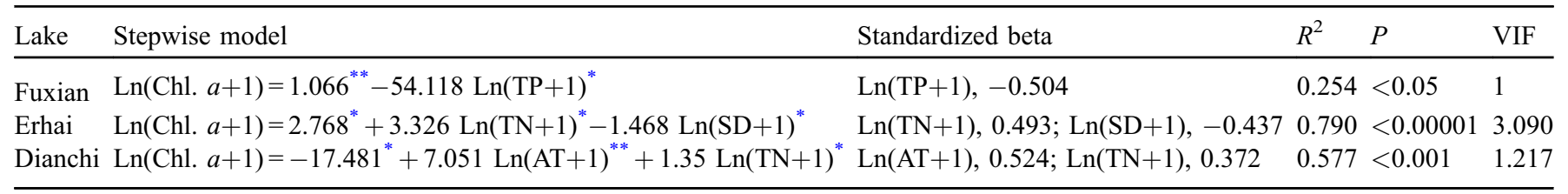

Chl. $a$, annual mean chlorophyll $a$ concentration; AT, annual mean air temperature; SD, annual mean water transparency; TN, annual mean total nitrogen; and TP, annual mean total phosphorus.

${ }^{*}$ Significance at $p<0.05$.

${ }^{* *}$ Significance at $p<0.01$.

species changed from Dolichospermum sp. to Microcystis sp. in Lake Erhai in 2010 (Wen and Ma, 2011). Microcystis sp. significantly contributed to the recent algal biomass in Lake Erhai. Dolichospermum sp. belong to functional group H1
(Reynolds et al., 2002; Padisák et al., 2009), which is particularly tolerant to low nitrogen and carbon conditions. This tolerance occurs because some $\mathrm{H} 1$ species possess nitrogen-fixation mechanisms, which favor them under 

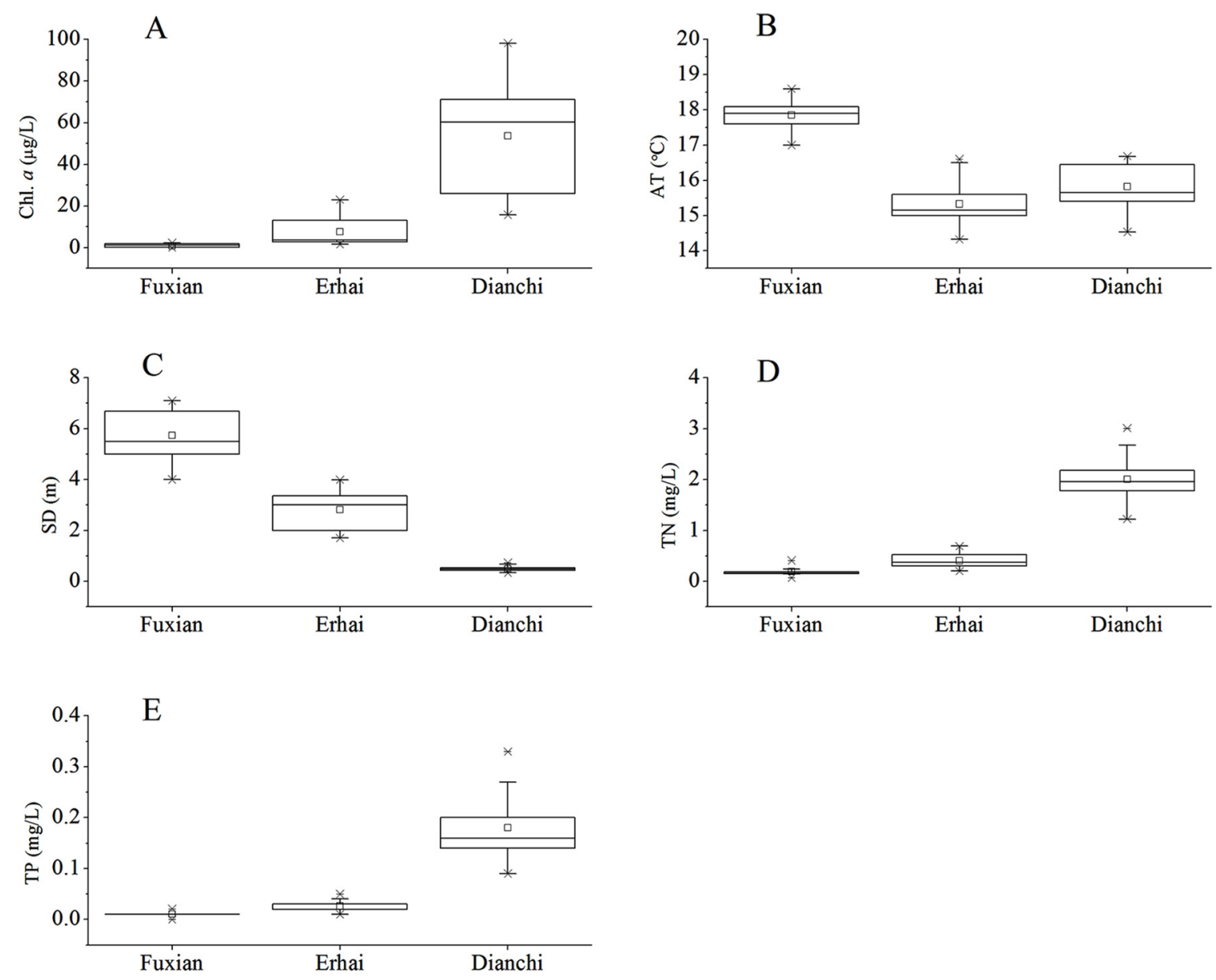

Fig. 4. ;Box chart of annual mean chlorophyll $a$ (Chl. $a$ ), air temperature (AT), water transparency (SD), total nitrogen (TN) and total phosphorus (TP) in the three lakes.

ambient low-nitrogen conditions. In the present study, the TN concentration in Lake Erhai increased by $0.017 \mathrm{mg} / \mathrm{L}$ per year from 1990 to 2010 and might have played a role in disrupting the dominance of Dolichospermum sp. This hypothesis is concordant with our results, which suggested that the increase in the algal biomass of Lake Erhai during the study period was positively correlated with TN concentration. From 1990 to 2010, the algal biomass of Lake Erhai was significantly negatively correlated with SD. This result is expected because Microcystis sp. is believed to be a resilient, shade-tolerant species. A similar result was reported by Kumagai (2000), who suggested that an increase in algal biomass associated with nutrient loading increased light attenuation in Lake Constance, thereby reducing water transparency. In addition, Rinke et al. (2010) demonstrated that this effect could promote thermal stratification, in turn creating a more stable environment for cyanobacterial growth. Although Microcystis sp. does not perform well in low light environments, it competes advantageously with other primary producers for light by vertically migrating to the surface (Rinke et al., 2010).

Lake Dianchi is hypereutrophic, and it currently exhibits year-round cyanobacterial blooms dominated by Microcystis sp. During the study period of 1990-2010, the dominant algae species in Lake Dianchi shifted from functional group $\mathrm{J}$ (consisting of Scenedesmus sp., Pediastrum sp. and
Coelastrum sp.) to assemblage M (consisting of Microcystis sp.) (details in Dong et al., 2014). Findlay et al. (2001) and Elliott et al. (2005) suggested that climate warming can modify existing phytoplankton communities and reported that warming is a predictor of algal biomass in this shallow lake, as high temperatures are more favorable to cyanobacteria than to green algae. During the study period, the increase in algal biomass of Lake Dianchi was significant and highly correlated with TN concentration and AT. This result agrees with those of Paerl and Paul (2012), who found that Microcystis sp. prefer high temperatures. Positive synergistic effects of warming and nutrition increases on Microcystis sp. biomass have also been observed in Lake Taihu (Deng et al., 2016) and Lake Pamvotis (Gkelis et al., 2014). Additionally, based on global-scale field data, Kosten et al. (2012) suggested that warming and increasing nutrient concentrations can increase cyanobacterial dominance in shallow lakes from subarctic Europe to southern South America.

Lake Fuxian was influenced by the AT increase during the 1960s (Dong et al., 2014). However, in the present study, unlike Lake Erhai and Lake Dianchi, Lake Fuxian exhibited no significant increase in AT or TN concentration from 1990 to 2010. However, significant increases in algal biomass were detected in Lake Fuxian. Based on an analysis of changes in phytoplankton composition, the filamentous green algae 
Mougeotia sp. is currently the most predominant species in Lake Fuxian (details in Dong et al., 2014). Additionally, the increase in the algal biomass of Lake Fuxian since the 1990s has been primarily associated with a sharp increase in the density of these green algae (Pan et al., 2009). In the present study, the increase in algal biomass in Lake Fuxian was negatively correlated with TP concentration. This result is consistent with that of Tapolczai et al. (2015), who indicated that meso-oligotrophic conditions ( $\mathrm{TP}<20 \mu \mathrm{g} / \mathrm{L}$ ) were favorable for Mougeotia sp. Additionally, Padisák et al. (2010) suggested that Mougeotia sp. is a permanent element of the phytoplankton flora in deep lakes, and its success is partially due to its ability to compete for phosphorus under low ambient concentrations (Reynolds, 2006).

The different responses of the three studied lakes to environmental conditions were very similar to those reported by Rigosi et al. (2014), who suggested that the effects of climate warming and eutrophication on cyanobacterial biomass were dependent on lake trophic state and taxon composition.

\section{Conclusion}

Lakes Fuxian, Erhai and Dianchi all exhibited increases in algal biomass over the studied time period of 1990-2010. Analyzing the effects of warming and nutrient levels on phytoplankton biomass in the three studied lakes revealed that the best predictor of algal increase varied among the lakes. The present findings demonstrated that nutrient levels had stronger effects than temperature in the oligotrophic lake (Lake Fuxian), whereas both nutrient levels and temperature affected algal biomass in the eutrophic and hypereutrophic lakes. This result supports the hypothesis that effects of climate warming and eutrophication on phytoplankton biomass are dependent on taxon composition of the lake.

Acknowledgments. The authors thank the hard-working generations of great scientists who collected the long-term monitoring data used in the present study. This work was jointly supported by the State Key Laboratory of Freshwater Ecology and Biotechnology (No. 2016FBZ07), the National Natural Science Foundation of China (No. 31500380 and No. 41601208), the Science and Technology Project of Henan Province (No. 152102310314) and the Science and Technology Project of Yunnan Province (No. 2016RA081).

\section{References}

Adrian R, Wilhelm S, Gerten D. 2006. Life-history traits of lake plankton species may govern their phenological response to climate warming. Glob Change Biol 12: 652-661.

Anneville O, Gammeter S, Straile D. 2005. Phosphorus decrease and climate variability: mediators of synchrony in phytoplankton changes among European peri-alpine lakes. Freshw Biol 50: 17311746.

Becker V, Caputo L, Ordóñez J, Marcé R, Armengol J, Crossetti LO, Huszar VLM. 2010. Driving factors of the phytoplankton functional groups in a deep Mediterranean reservoir. Water Res 44: 3345-3354.

Brookes JD, Carey CC. 2011. Resilience to blooms. Science 334: 4647.
Cai Q. 2007. Protocols for standard observation and measurement in aquatic ecosystems, Beijing: Chinese Environmental Science Press.

Coumou D, Robinson A, Rahmstorf S. 2013. Global increase in record-breaking monthly-mean temperatures. Clim Change 118: 771-782.

Deng JM, Qin BQ, Sarvala J, Salmaso N, Zhu GW, Ventelä AM, Zhang YL, Gao G, Nurminen L, Kirkkala T, Tarvainen M, Vuorio K. 2016. Phytoplankton assemblages respond differently to climate warming and eutrophication: a case study from Pyhäjärvi and Taihu. J Great Lakes Res 42: 386-396.

Dong BJ, Liu JS, Zhu YW, Yang Z. 2008. Study on the air temperature and rainfall characteristics of Dali city, China, in the last 45 years. China meteorological society 2008 convention on climate change at the venue (in Chinese).

Dong C, Wu L, Lin P, Shan YP, Tan XM. 2012. Climate changing on landscape environment in Kunming in recent 60 years. Shandong For Sci Technol 3: 6-11 (in Chinese).

Dong J, Li GB, Song LR. 2014. Historical changes of phytoplankton functional groups in Lake Fuxian, Lake Erhai and Lake Dianchi since 1960s. J Lake Sci 26: 735-742 (in Chinese).

Dong J, Zhou WC, Song LR, Li GB. 2015. Responses of phytoplankton functional groups to simulated winter warming. Ann Limnol - Int J Lim 51: 199-210.

Elliott JA. 2012. Predicting the impact of changing nutrient load and temperature on the phytoplankton of England's largest lake, Windermere. Freshw Biol 57: 400-413.

Elliott JA, Thackeray SJ, Huntingford C, Jones RG. 2005. Combining a regional climate model with a phytoplankton community model to predict future changes in phytoplankton in lakes. Freshw Biol 50: 1404-1411.

Elliott JA, Jones ID, Thackeray SJ. 2006. Testing the sensitivity of phytoplankton communities to changes in water temperature and nutrient load, in a temperate lake. Hydrobiologia 559: 401-411.

Feuchtmayr H, Thackeray SJ, Jones ID, De Ville M, Fletcher J, James B, Kelly J. 2012. Spring phytoplankton phenology are patterns and drivers of change consistent among lakes in the same climatological region? Freshw Biol 57: 331-344.

Findlay DL, Kasian SEM, Stainton MP, Beaty K, Lyng M. 2001. Climatic influences on algal populations of boreal forest lakes in the Experimental Lakes Area. Limnol Oceanogr 46: 1784-1793.

Fu H, Yuan GX, Cao T, Zhong JY, Zhang XL, Guo LG, Zhang M, Ni LY, Wang SR. 2013. Succession of submerged macrophyte communities in relation to environmental change in Lake Erhai over the past 50 years. J Lake Sci 25: 854-861 (in Chinese).

Gao W, Chen Y, Xu M, Guo HC, Xie YC. 2013. Trend and driving factors of water quality change in Lake Fuxian (1980-2011). J Lake Sci 25: 635-642 (in Chinese).

Gkelis S, Papadimitriou T, Zaoutsos N, Leonardos I. 2014. Anthropogenic and climate-induced change favors toxic cyanobacteria blooms: evidence from monitoring a highly eutrophic, urban Mediterranean lake. Harmful Algae 39: 322-333.

$\mathrm{Gu}$ GH. 2008. Analysis of water temperature characteristics and trend in Fuxianhu Lake. Pearl River 5: 38-39 (in Chinese).

Huang HJ, Wang YP, Li QH. 2010. Evaporation variation from Erhai Lake and its controls under climatic warming. J Meteorol Environ 26: 32-35 (in Chinese).

Huang XF, Chen W, Cai Q. 2000. Survey, observation and analysis of lake ecosystem, Beijing: China Standards Press.

Huber V, Wagner C, Gerten D, Adrian R. 2012. To bloom or not to bloom: contrasting responses of cyanobacteria to recent heat waves explained by critical thresholds of abiotic drivers. Oecologia 169: 245-256. 
Jeppesen E, Meerhoff M, Holmgren K, González-Bergonzoni I, Teixeira-de Mello F, Declerck SAJ, de Meester L, Søndergaard M, Lauridsen TL, Bjerring R, Conde-Porcuna JM, Mazzeo N, Iglesias C, Reizenstein M, Malmquist HJ, Liu ZW, Balayla D, Lazzaro X. 2010. Impacts of climate warming on lake fish community structure and dynamics, and potential ecosystem effects. Hydrobiologia 646: 73-90.

Jöhnk K, Huisman J, Sharples J, Sommeijer B, Visser PM, Stroom JM. 2008. Summer heatwaves promote blooms of harmful cyanobacteria. Glob Change Biol 14: 495-512.

Köhler J, Hilt S, Adrian R, Nicklisch A, Kozerski HP, Walz N. 2005. Long-term response of a shallow, moderately flushed lake to reduced external phosphorus and nitrogen loading. Freshw Biol 50: $1639-1650$.

Kosten S, Huszar VLM, Bécares E, Costa LS, Van Donk E, Hansson LA, Jeppesen E, Kruk C, Lacerot G, Mazzeo N, Meester LD, Moss B, Lürling M, Nõges T, Romo S, Scheffer M. 2012. Warmer climates boost cyanobacterial dominance in shallow lakes. Glob Change Biol 18: 118-126.

Kumagai M. 2000. Seeking wisdom in limnology. Limnology 1: 1-2. Li GB, Li L, Pan M, Xie ZC, Li ZS, Xiao BD, Liu GH, Chen J, Song LR. 2014. The degradation cause and pattern characteristics of Lake Dianchi ecosystem and new restoration strategy of ecoregion and step-by-step implementation. J Lake Sci 26: 485-496 (in Chinese).

Li ZK, Yang PP, Su SF. 2015. Eutrophication trend of Erhai Lake from 2004 to 2013. Environ Sci Surv 34: 1-3 (in Chinese).

Liu Z, Liu X, Chen Y. 2011. The effects of temperature and nutrient ratios on Microcystis blooms in Lake Taihu, China: an 11 year investigation. Harmful Algae 10: 337-343.

Mooij WM, Hülsmann S, De Senerpont Domis LN, Nolet BA, Bodelier PLE, Boers PCM, Miguel Dionisio Pires L, Gons HJ, Ibelings BW, Noordhuis R, Portielje R, Wolfstein K, Lammens EHRR. 2005. The impact of climate change on lakes in the Netherlands: a review. Aquat Ecol 39: 38-400.

Moss B, Mckee D, Atkinson D, Collings SE, Eaton JW, Gill AB, Harvey I, Hatton K, Heyes T, Wilson D. 2003. How important is climate? Effects of warming, nutrient addition and fish on phytoplankton in shallow lake microcosms. J Appl Ecol 40: 782-792.

O'Neil JM, Davis TW, Burford MA, Gobler CJ. 2012. The rise of harmful cyanobacteria blooms: the potential roles of eutrophication and climate change. Harmful Algae 14: 313-334.

Ouyang ZH, Guo HC, Wang WJ, Gao W. 2015. Analysis of water quality change and impacts from socio-economic development in Lake Dianchi from 1982 to 2012. Environ Monit China, 31: 68-73.

Padisák J, Crossetti LO, Naselli-Flores L. 2009. Use and misuse in the application of the phytoplankton functional classification: a critical review with updates. Hydrobiologia 621: 1-19.

Padisák J, Hajnal É, Krienitz L, Lakner J, Üveges V. 2010. Rarity, ecological memory, rate of floral change in phytoplankton and the mystery of the Red Cock. Hydrobiologia 653: 45-64.

Paerl HW, Huisman J. 2008. Climate - blooms like it hot. Science 320: $57-58$.

Paerl HW, Huisman J. 2009. Climate change: a catalyst for global expansion of harmful cyanobacterial blooms. Environ Microb Rep 1: $27-37$.
Paerl HW, Paul VJ. 2012. Climate change: links to global expansion of harmful cyanobacteria. Water Res 46 1349-1363.

Pan JZ, Xiong F, Li WZ, Ke F. 2009. Structure, distribution and its impact factors of phytoplankton community in Fuxian Lake. Acta Ecol Sinica 29: 5376-5385 (in Chinese).

Posch T, Köster O, Salcher MM, Pernthaler J. 2012. Harmful filamentous cyanobacteria favoured by reduced water turnover with lake warming. Nat Clim Change 2: 809-813.

Reynolds CS. 2006. The ecology of phytoplankton. Cambridge University Press.Cambridge

Reynolds CS, Huszar V, Kruk C, Naselli-Flores L, Melo S. 2002. Towards a functional classification of the freshwater phytoplankton. J Plankton Res 24: 417-428.

Rigosi A, Carey CC, Ibelings BW, Brookes JD. 2014. The interaction between climate warming and eutrophication to promote cyanobacteria is dependent on trophic state and varies among taxa. Limnol Oceanogr 59: 99-114.

Rinke K, Yeates P, Rothhaupt KO. 2010. A simulation study of the feedback of phytoplankton on thermal structure via light extinction. Freshw Biol 55: 1674-1693.

Sheng H, Liu H, Wang C, Guo H, Liu Y, Yang Y. 2012. Analysis of cyanobacteria bloom in the Waihai part of Dianchi Lake, China. Ecol Inform 10: 37-48.

Tadonléké RD. 2010. Evidence of warming effects on phytoplankton productivity rates and their dependence on eutrophication status. Limnol Oceanogr 55: 973-982.

Tapolczai K, Anneville O, Padisaák J, Salmaso N, Morabito G, Zohary T, Tadonléké RD, Rimet F. 2015. Occurrence and mass development of Mougeotia spp. (Zygnemataceae) in large, deep lakes. Hydrobiologia 745: 17-29.

Taranu ZE, Zurawell RW, Pick F, Eavas IG. 2012. Predicting cyanobacterial dynamics in the face of global change: the importance of scale and environmental context. Glob Change Biol 18: 3477-3490.

Wagner C, Adrian R. 2009. Cyanobacteria dominance: quantifying the effects of climate change. Limnol Oceanogr 54: 2460-2468.

Walters AW, Sagrario MdlÁG, Schindler DE. 2013. Species- and community-level responses combine to drive phenology of lake phytoplankton. Ecology 94: 2188-2194.

Wen HX, Ma GL. 2011. Study of water quality and algae in Erhai Lake during 2008-2010. Environ Sci Manage 36: 44-48 (in Chinese).

Yu D, Li FR, Wang JT. 2013. Water environment evolution and algae monitoring technology development in Lake Dianchi. Environ Sci Surv 32: 53-57.

Zhang M, Duan HT, Shi XL, Yu Y, Kong FX. 2012. Contributions of meteorology to the phenology of cyanobacterial blooms: implications for future climate change. Water Res 46: 442-452.

Zhou J, Liang Z, Liu Y, Guo H, He D, Zhao L. 2015. Six-decade temporal change and seasonal decomposition of climate variables in Lake Dianchi watershed (China): stable trend or abrupt shift? Theor Appl Climatol 119: 181-191.

Zhou QC, Zhang YL, Lin DM, Shan K, Luo Y, Zhao L, Tan ZW, Song LR. 2016. The relationships of meteorological factors and nutrient levels with phytoplankton biomass in a shallow eutrophic lake dominated by cyanobacteria, Lake Dianchi from 1991 to 2013. Environ Sci Pollut Res 23: 15616-15626.

Cite this article as: Dong J, Zhou Q, Gao Y, Gu Q, Li G, Song L. 2018. Long-term effects of temperature and nutrient concentrations on the phytoplankton biomass in three lakes with differing trophic statuses on the Yungui Plateau, China. Ann. Limnol. - Int. J. Lim. 54: 9 